\title{
Regulations in National Laws on Construction in Coastal Areas
}

\author{
Abdolmohammad Afrough' \\ Syed Bagher Mirabbassi" \\ Abumohammad Asgarkhani"I \\ Maryam Moradi ${ }^{i v}$
}

\begin{abstract}
The coasts and the sides of the sea, the forehead of the lands and, consequently, are the forefront of the national lands. Our sustained and deep effort in coastal and port management and engineering is a special part of the ethical responsibility of the Ports and Maritime Organization and from this, the fate of the beauty and purity of coasts and ports is deeply tied to the fate of the type and form of exploitation of the coast. Therefore, the present study was carried out with the purpose of collecting and integrating existing national laws in the field of construction in coastal and port areas and determining the weak points and ambiguities of existing regulations. Previous studies have been done in detail and in several publications and regulations, while existing and valid regulations throughout the world are comprehensive in the form of a book or journal. Due to the scatter of domestic publications and the absence of a comprehensive source in this study, these journals have been thoroughly and comprehensively presented as a book or journal. The design of coastal structures is designed to create harmony and uniformity in the design, construction, monitoring, and implementation of coastal structures and related projects, as well as to observe the principles, methods and technologies appropriate to the equipment and adapted to the requirements. The country is being prepared and compiled and, in addition to using the feedbacks received from the journals number 300, the guidelines and technical texts presented with the new standards of the standards and other national regulations have also been harmonized and in cases where national standards and criteria are not available, international standards should be used. The paper also attempts to make the publication available in such a way that due to the limited access to the standards and regulations and in order to expand the culture of technical knowledge and transfer it to the design and implementation of the projects, the contents of the guidelines and technical regulations necessary to provision is made to users.
\end{abstract}

Keywords: Port; Coastal structures instruction; Collecting laws; Coastal construction

\footnotetext{
' Department of Public International law student, Qeshm International Branch, Islamic Azad University, Qeshm, Iran a.afrough@aftermail.ir

" Department of Public law, Political Science, University of Tehran, Tehran, Iran Corresponding Author: b.mirabbassi@aftermail.ir

I'IDepartment of International Relation, Political Science Faculty, University of Tehran, Tehran, Iran a.asgarkhani@aftermail.ir

IVDepartment of Public International law, Qeshm International Branch, Member of Islamic Azad University, Qeshm, Iran m.moradi@aftermail.ir
} 


\section{Introduction}

Iran with more than $3000 \mathrm{~km}$ of coastline is one of the most stable countries in the world. Therefore, it is necessary to design, construct, rebuild and strengthen marine structures in the coastal regions of Iran. Among other things, docks and decks are considered for more reasons. In designing this berth, the various criteria recommended in the regulations for marine equipment should be taken into consideration. These criteria include the effects of atmospheric agents on the life of the structure and its extraordinary circumstances. Therefore, the importance and use of these structures require a closer look at this issue. Proper design and implementation of infrastructure and development projects in coastal areas require accurate information on the environmental conditions and hydrodynamic conditions of the relevant area. Waves and winds are considered as important parameters in the design of coastal and offshore structures. Determining the characteristics of wind and wave with high return periods for the design of marine and terrestrial structures and field studies is essential in many marine engineering projects. The wind and wave analysis of Iran's seas was conducted using its simulated results for the first time in the form of Iran's wave-wave modeling project by the National Oceanographic Center. However, the favorable and economical position of coastal and offshore structures requires such an analysis. Physical and chemical degradation factors including corrosion enhancement in concrete, sulfate attacks, concrete carbonate, stress caused by crystallization of salts in concrete cavities, as well as hydraulic forces, etc., on the one hand, along with weather parameters on the other hand, this is one of the factors that has led to the formation of acute conditions for the destruction of a wide range of concrete structures in the region. While appreciating the shortage of beaches in the south for domestic and foreign experts, we can say that less effort has been made to report on the importance of this region for addressing this issue.

Throughout history, beaches and port cities are considered to be one of the most attractive and economical settlements for human beings due to the favorable climate conditions, commercial and transportation, tourism, agriculture, and aquaculture. Therefore, the aggravation of population density in the coastal strip and port cities during recent 
decades has resulted in the definition of optimal and sustainable exploitation of coastal areas and resources within the framework of regional and sustainable coastal economy models and based on several criteria and standards. In this way, management and oversight of coastal waters, ports, and offshore structures have a new and more complete concept with several goals of sustainable conservation and exploitation of coastal areas. Hence, in line with global developments of management and science, exploitation of ports and coasts, such as the development of the first, second and third generations in industrial ports and clusters, tourist and offshore prominences along the coast, the duties of the sovereignty of upgraded port organizations and the use and use of management, economic, and social expertise along with technical and engineering expertise that mainly focuses on the mechanical functions of maritime organizations, has been crucial in the planning, management, and supervision of beaches, ports and marine structures. It deserves to be considered seriously by the organizations, organs and private and public institutions sea country.

Fortunately, in our country, this important issue has been well explained in the form of Article 63 of the fourth development plan law, and its implementing strategies have been set up by the ports and maritime organization, with the aim of establishing integrated management in coastal areas, environmental standards, and maritime navigation and this important responsibility is formulated and implemented in the valuable studies of this organization. Therefore, due to national and international developments in the management of beaches, ports and marine structures, as well as the emphasis of the minister of railways and urban development on the special attention to the sea-based economy in port cities and coastal areas, the strengthening of the economic functions of beaches and ports in life coastal people should be more and more urgent and it is imperative that port organizations respond appropriately to the needs of this important sector within the framework of the water economy by refurbishing their structures.

Today, about 90 percent of the world trade is transported through seas and shipping, and the role and importance of ports as marine transport in responding to this massive volume of goods and passengers are increasingly evident. In neighboring countries, beaches 
are considered as the focus of economic activities, including trade, industry, and transportation of goods and passengers, recreation, tourism and fisheries, and aquaculture, and at all times have the ideal opportunities for economic development and large investments. Solving the technical and executive problems of construction of coastal and offshore structures in the marine environment and the huge costs of such structures and engineering facilities, special attention to designing the right engineering and appropriate according to standards, standards and design criteria is more than necessary. Coastal areas are among the most vulnerable to climate change and natural hazards. Since people's welfare and economic efficiency in many businesses in coastal areas depend on the environmental status of these areas and given the increasing development of coastal areas and unplanned constructions, and consequently an unhealthy population increase in these areas, it was necessary to prevent the extensive destruction and pollution of the coastline. In order to increase the protection of coastal resources and increase the productivity of these areas, and considering the wide range of resources, laws and regulations are integrated in a comprehensive manner. The design of coastal structures in Iran consists of 11 sections, each of which is an independent journal issue. The purpose of the designing and implementation of coastal protection instruments is to provide a comprehensive and comprehensive set of common and appropriate methods for coastal protection according to the conditions. Comparing foreign standards in a comprehensive manner and considering the conditions of each region and in the wider area and in addition to building construction methods. By examining journals, letters and internal and external books, it can be concluded that sometimes different methods of coastal protection and attention to the performance of various structures in coastal protection, in the stages of study, design, and implementation, have a direct effect on the optimal it will create the desired design and make it more economical.

The 11th International Conference on Coastal, Ports and Marine Structures in the country suggests that the Ports and Maritime Organization's serious participation in the flow of social responsibility towards coastal areas, offshore, environment and coastal and coastal management will certainly be possible. It is explained that national ideas in support of the sustainable development of harbors, ports, and beaches, and efforts to curb the expansion 
of polluting structures and facilities. It also provokes the hope that irrespective of the power structure that is not capable of responding to the most basic needs of the survival of the human species, we are promising decisive solutions to the protection of human civilization, the environment, and sustainable development. Strengthening technical cooperation between countries in the region and the world, and providing researchers and experts with the capabilities of the local and international community is a wise strategy for deployment, with the lowest levels of coastal destruction and the environment. The beaches and the sides of the sea, the forehead of the lands and, consequently, are the forefront of the national lands. Our sustained and deep effort in coastal and port management and engineering is a special part of the ethical responsibility of the Ports and Maritime Organization and from this, the fate of the beauty and purity of beaches and ports is deeply tied to the fate of the type and form of exploitation of the coast. At this point, issues such as the continuation of coastal industrialization, the continued development of residential and residential texture on the coast, the continuation of agricultural and fishery activities, and so on, have now become "problematic" issues. In other words, the status of these issues has been upgraded to the level of national, regional and global issues. The coastal areas, like the seas, are the wealth and Commonwealth of Nations, and each member of the group is the shareholder of this global capital.

This membership also creates a common duty. The common duty in the creation of a "universal exploitation" that derives from this "wealth and capital" is to benefit all the peoples of the world.

Referring to the above, the importance of ports for everyone is clear, therefore, due to the importance and necessity of this issue, it is necessary to collect and compile a set of specific laws for integrated management of these areas. The general objective of this research is to collect and integrate existing national construction laws and regulations in coastal and port areas and to determine the weaknesses and ambiguities of existing regulations. 


\section{Research literature}

Bijeny (2011) conducted a research to evaluate and simulate physical changes in the coastal zone of Noshahr and Chalus using the RS and GIS technique and its adaptation to the principles of integrated coastal zone management (ICZM), and found that the preparation and implementation of comprehensive plans protection in order to balance the exploitation, reduce resource degradation and achieve sustainable development always requires the planning of development programs in the coastal zone. The results indicate that the areas that were built in the study area were abandoned, which significantly reduced the size of the gardens and agricultural lands and given the limited area of the coastal zone, the continuation of this trend in the coming years can have many of the capabilities and capabilities of this area (1).

Ramezani and Taleghani (2012) conducted a research to get an integrated environmental management approach for organizing the coast of the country, they found that the coastal areas of the country were developed regions that, as an interconnected bridge with other countries of the world, facilitated the internal and external relations of the country's economy and helped to create regional equilibrium, use of the geographical and regional situation of the country, the sustainable use of resources, capabilities and environmental protection, guarantee the security of the inner regions through the borders of the country and, in general, act as a symbol of the country's development (2).

Sheikhi and Azimi (2013), in a study entitled "environmental management in coastal areas of cities emphasizing the management of the Caspian Sea coast and considering that in many countries, the protection of the sea and the prevention of any unplanned construction in that aspect efforts of the authorities have been taken. Using the library method and field observation, they examined the process of handcuffs on the northern coast of the country in the years before and after the revolution. The results of this study showed that a major part of the problems in the Caspian coastal zone was caused by human factor interference and the application of cross-sectional, inconsistent and unplanned policies and policies has led to the process of these destructions (3). 
Behnoud (2014) conducted an investigation into the origin of sediments and estimated the sediment transport rate of the coast in a less developed coastal section of Sistan and Baluchistan province. He found that it is important to discuss the extent of sedimentation and sediment production in coastal areas and its effects on coastal marine habitats because one of the measures currently being taken into account in the development of coastal development projects and can be reviewed in the course of completing and correcting inappropriate trends and problems in the plans, is the debate about the amount of sedimentation. Using satellite imagery, it was also found that after the construction of the docks, the western shores experienced erosion and ascension, while sedimentation was evident on the eastern shores of the pier (4).

Yousefi and Kordvani (2014), carried out research aimed at determining the efficiency of the current privacy of the Caspian Sea and landscapes and geomorphological hazards caused by fluctuations in the level of the Caspian Sea surface with the progressive attitude of human construction in the city of Babolsar. From the results of this study, the determination of the fluctuation of the Caspian Sea level during the past 176 years was 3.75 m, and the sharp increase between 1976 and 1974 was about 2.53 m, which is about 302 $\mathrm{km} 2$ from the coastal area of Mazandaran province and about $1.40 \mathrm{~km} 2$ It has been submerged from the beaches of Babolsar, which indicates the inefficiency of the coastal area of the Caspian Sea. The width of the Caspian Sea is 60 meters from the last water improvement point in 1342, the results of this study show that the elevation of the Caspian Sea surface has led to a coastline of between 50 and 100 meters and practically, the Law on the Protection of the Caspian Sea and the lands of the Caspian Sea will lose its scientific and technical efficiency (5).

Hossein Zadeh et al. (2016) conducted a study in 1959 to investigate the role of geomorphologic indices in the construction of Mahmoudabad coastal area. In this research, the Coastal Vulnerability Index (CVI) was used as a geomorphic index in the construction of the coastal area of the city and city of Mahmoudabad. Subsequently, by determining these ranges, it was determined those 32.22 square kilometers, 12.23 percent of the total land area of the city was located in the range of primary and secondary vertical squares. Following this 
discussion and within the area of primary and secondary vertical range, the coastal vulnerability index based on 5 parameters of elevation, slope, geomorphology, land use, and distance from the road in two sub-indices of natural and human origin were performed. Based on the final map of coastal vulnerability, classes with high and high vulnerability include $21.6 \%$ of the land with an altitude lower than 23.5 meters (6).

Sorti et al. (2017) carried out an investigation into the changes in the coastline of the southern coast of the Caspian Sea during the period of 1987-1987, in their view, monitoring and protecting coastal zone changes is a critical part of the Coastal Zone integrated management program to achieve sustainable development. Therefore, the preparation of coastline maps and the extent of their changes to plan and use the beaches is very necessary. The study area in their study covers the southern coast of the Caspian Sea around the ports of Amirabad and Sadra (Neka). In addition, the amount of sedimentation and erosion in the area was also calculated. The research findings indicate that the coastline has progressed to the sea during most of the two studied periods and has eroded only in the eastern parts of the ports of Amirabad and Sadra (Neka). The highest coastal lineage and retreat from 1987 to 2001 were 450 and 68 meters respectively. In addition, the total amount of sedimentation and erosion carried out on the coast of the region from 1989 to 2015 was about 5.69 square kilometers and 0.53 square kilometers (7).

\section{Research method}

\subsection{Study of the experiences and laws in the field of determining the bedding and the boundaries of the watershed}

The following is a brief overview of the coastal laws of the country and is discussed around their work and their relationship. Also, the experiences of other countries in this field are discussed and finally, a compilation and appropriate model for our country is presented.

\subsection{Examining Coastal Laws of the Country}

These laws are in some way related to each other, that is, the law on the fair distribution of water regarding the seabed and seabed, lakes and wetlands is subject to the 
law of the coastal land, and the approval of the High Council of Architecture and Urban Planning, due to the ineffectiveness of the Caspian Sea Coastal Law and Article 63 of the Fourth Development Plan Law for the Review and Determination of Territory, which the law has declared 60 meters, as well as the liberalization of the coast with emphasis on the Caspian Sea has been approved. Below, these regulations are discussed briefly in the light of the objectives of this guide (8).

\subsection{Coastal and land legislation}

This law determines the land area for the Caspian Sea only, while for the Oman Sea, the Persian Gulf and Lake Urmia the coastal land has been identified. Due to high volatility in the area of lakes, due to the high volatility of the land, the scope of the natural activities of these watersheds is one of the strengths of this law. Also, the determination of coastal lands for free seas seems to be appropriate due to periodic fluctuations. But the legislator for coastal waters has set a certain distance from the blue zone, which may in practice cause some of the natural phenomena associated with water zones and sensitive environmental points outside this distance. This law defines the law for Caspian and Urumia lakes and the Gulf of Oman and the Persian Gulf. This limit for lakes is 60 (horizontal) (from the origin of time) and for the Oman Sea and the Persian Gulf as a horizontal distance (sixty meters) is considered from the last point of fashion. In the case of the Caspian Sea, the mentioned privacy is considered in most of the areas in the lands of the Ustad-e-Shah, which itself is considered as a bed of this blue zone and has led to the ineffectiveness of this law, especially in the recent advances of the Caspian Sea. It has also been stipulated in this law that in the case of other lakes and wetlands of the country, the proposals submitted by the Ministry of Agriculture and Natural Resources (Ministry of Jihad-e-Agriculture) should be submitted and approved by the Cabinet of Ministers, which was not reached before 2008. But according to the proposal No. 2795/0202 / dated 14/08/2006 of the Ministry of Agriculture and on the basis of Note (2) of Article 2 of this Law, the executive order of the note mentioned above was approved by the Ministerial Council No. 36396 dated 36256 dated 19/01/2008 in this 
resolution, the width of the area of the wetlands (except for the lagoon and natural pond) is an area of 150 meters in width, which is immediately determined after the bed limit (9).

\subsection{Review of the experience of determining the bedding and coastal area of other countries}

The coastal regulations of different countries of the world are based on the climatic and natural conditions of the water zones of each region and are different according to the methods of exploitation of coastal lands and their coastal management plans. On the other hand, in view of the tsunami phenomenon (2004) in the countries of Southeast Asia, and the widespread economic and social losses, the issue of observance of safety and warning systems in the agenda of the countries of the region and relevant international organizations and for this reason it seems that in the future there will be wider variations in the issues of determining the boundaries and boundaries of water zones, especially for the oceans and seas. But with a review of the experiences of different countries, the seabed is based on the highest water level in astronomical fashion, storm breakdown, and periodic water level changes, while the boundaries of the boundaries are completely contractual, and each country has a different width based on Coastal and environmental activities have been put into practice. Table 1) shows the boundaries of coastal areas in a number of countries (9).

Table 1 - The boundaries of sea and land borders in different countries (9)

\begin{tabular}{l|l|c}
\hline Country & Sea bed limit & Limit (m) \\
\hline Finland & Average water line & 50 to 200 \\
\hline Greece & $\begin{array}{l}\text { The border of the tallest waves of } \\
\text { the winter }\end{array}$ & 50 \\
\hline Lithuanian & Highest tide waves & 300 \\
\hline Norway & Highest water height & 100 \\
\hline Portugal & $\begin{array}{l}\text { The highest watermark in } \\
\text { astronomical fashion }\end{array}$ & 500 \\
\hline
\end{tabular}




\begin{tabular}{l|c|c}
\hline Spain & Highest astronomical fashion & 100 to 200 \\
\hline Sweden & The highest watermark & 100 to 300 \\
\hline England & The highest watermark & - \\
\hline America (Calif) & $\begin{array}{l}\text { Flexible for states (the highest } \\
\text { mark of sea mode) }\end{array}$ & $\begin{array}{c}\text { Flexible for states } \\
\text { 4.914 equivalent to } 1000 \\
\text { yard }\end{array}$ \\
\hline India & Highest astronomical fashion & 100 to 500 \\
\hline Sri Lanka & The highest watermark & $\begin{array}{c}100 \text { to } 200 \\
\text { New } 300 \text { to } 700\end{array}$ \\
\hline \multicolumn{1}{c|}{ Indonesian } & The highest watermark & $\begin{array}{c}\text { (2000 Proposal after } \\
\text { tsunami) }\end{array}$ \\
\hline
\end{tabular}

\subsection{The spirit of the ruler on a design instruction}

Generally, the spirit of the design guidelines is to provide simple and practical criteria in the form of a number of guidelines and guidelines that, while easy and efficient, with sufficient scientific backing and experience, can provide a predictable and acceptable range of properties for the construction industry. Under different forces, in other words, the main purpose of a design instruction is as follows. In a rational framework, with due regard to the appropriate safety margin, a set of general and partial policies and guidelines and general lines of motion for the designer, in such a way that the design is reliable and reliable, and the designer without dealing with a large number of parameters, and only with a few major and influential variables, are capable of designing a construct defined in the field of application of the instructions to an acceptable level of accuracy and at an appropriate level of safety (10).

Although the ease of use is one of the most important features in designing a design instruction, however, in no case should safety be sacrificed for this ease of use. Of course, it's also important to note that if lowering the safety level leads to a weakness of an instruction, instead of excessive conservatism, it can lead to the justifiableness of the rules of the guidelines economically. Obviously, knowing the structure and philosophy of an 
instruction, its scope, its weaknesses, and its strengths and issues behind its seemingly simplistic instructions makes it easier to use the desired instruction (10).

\subsection{Essential Requirements for a Coastal Structures Design Instruction}

The geographical and climatic conditions of countries with a credible guide to the design of coastal structures that have a long coastline in the Pacific Ocean and Atlantic Oceans have led to special attention to coastal technical issues and coastal protection in accordance with their coastal needs. With regard to their maritime history, they are instructed in the form of technical regulations and presented throughout the history in accordance with the industrial conditions and it is evident to the advancement of science at different stages of time, these instructions also affected by the results of extensive field and laboratory research, and of course expensive price has been updated. It is worthwhile mentioning that the recent category, namely, gaining assurance about the accuracy of the obtained results and their adaptation to the actual situation is considered as the most important and complex step in the formulation of a design of coastal structures, because the factors and parameters involved in each of the technical criteria of extraction it is so numerous and diverse. A glance at the current state of the country from the point of view of the special needs for the purpose of designing the design of coastal structures is the beginning of attention and the initial activity for realization of the problem, but the time constraints prevent the current course from continuing to be achieved in the classical way (11).

On the other hand, the extent of the coastal waters on the one hand and the need for different port complexes, on the other hand, necessitate the existence of a reliable technical reference containing the criteria and guidelines for the design and implementation of various coastal structures in the minimum possible time. With a rational attitude to the need for access to a credible and quality-qualified instruction in a very short time, the only solution is to leave a selection of a valid and validated instruction as a basis with maximum compliance with the engineering conditions of Iran (12). 


\subsection{Essentials and the need to select a basic instruction}

In principle, one of the most important indicators in the development of any engineering instruction is the coherence and coordination of its various parts. The importance of this issue will be doubled when the instructions have a wide variety of different sections. Establishing a logical connection between various technical issues on the one hand and the need to establish a technical balance between these topics is, on the other hand, the main reasons and the philosophy of the coherence of existence referred to in each report and a technical set of rules, such as an engineering instruction. Therefore, it can be seen that in order to achieve an optimal coherence in one instruction, one has to have a single engineering approach in the compilation of its different parts, and the use of different perspectives cannot lead to a proper coherence in the macro of an instruction. Obviously, if a special expert group composed of fan experts on a particular topic and in the form of a technical team task from the beginning to the end of the preparation and development of the bases and details of an engineering instruction, finally, it can be expected that the final result has the necessary coherence in the direction of the instruction, otherwise, the choice of various technical topics from a set of existing and even valid international guidelines cannot, at the end, guarantee the formation of a coherent technical set. Because different sections of the selected different instructions are prepared with their own working group views and they are necessary in the form of their collection. As soon as these different topics are combined, they have found an inconsistency between them and the final result, that is, a desirable technical instruction; will not be achieved (13).

It is reiterated that the most important characteristic expected from the coherence between the various issues of an instruction is the establishment of a technical balance between them. The purpose of this technical balance is that the results of the application of the rules of the instructions in practice lead to conservatism and excessive tightening, or vice versa, an unusual simplicity in design. In this framework, it's important to note that basically, the rules of an engineering code that is the product of the approach of its formulators should not be so conservative that the resulting design results are considered non-economic. Nor should it be designed to be safe. Therefore, it should be noted that in the meantime 
establishing an appropriate engineering relationship between the different criteria for designing an instruction should ultimately lead to the provision of an optimized product, and this will not be achieved unless one instruction is used.

In the past, the experiences and backgrounds about the blind use of various topics from different guidelines for designing a problem have been indicative of undesirable results on the economics of the design, or that they were not immune to both, which, in terms of engineering, were rejected. Normally, the creation of a technical balance between different criteria extracted from different instructions is not in the capacity of the designers and it is almost impossible to implement it in practice and in engineering terms (14).

\section{Findings}

\subsection{The effect of time parameter on the design of coastal structures}

In the conventional case, the process of preparing and designing a good and acceptable engineering instruction is a long-term process and if the time for the development of valid technical guidelines in the field of engineering in the world is evaluated, it will be seen that this time is usually remarkable and be investigating the foundations influencing the design of technical design and evaluating all aspects of the matter, including loading and analyzing their behavior in the formulation of the desired criteria, is very necessary and necessary, because the lack of attention to each of the effective variables can be in the desired conclusion, has a bad effect. Obviously, as much as possible, the objects and their spatial environments differ from the usual state of construction, in other words, the complexity of the influential factors and, therefore, the desired time. In this regard, in order to clarify the unconventional behavior of the building, it is necessary to carry out numerous field and laboratory tests as well as environmental measurements for determining the loading. Perhaps for this reason, the number of credible guidelines for the design of coastal structures in the world is very limited and limited in comparison with other civil engineering fields. The long time is necessary for the proper evaluation of all the effective parameters for the design of coastal structures on one side and the enormous costs 
of these complex assessments. On the other hand, it is usually the case for marine administrators and carriers to persuade the use of valid credentials in most countries.

\subsection{Overview of maritime regulations and selection of basis of legislation}

If the concepts of the previous materials are properly evaluated and understood, considering the current situation in the design and implementation of marine structures in the form of port complexes required by the country and basically, the issues related to the design of coastal structures should be short-term with a rapid process, the goal is to have a solid set of marine construction design criteria and equipment. In this regard, and according to the technical requirements mentioned as the basic concepts of an instruction, a way to study some valid regulations in the field of coastal structures design and finally choose one of them as the main framework of the rules of the design of coastal structures of Iran not left. Of course, it is again noteworthy that this way in such situations and in fact, with regard to all aspects of the matter, is the best way to achieve the goal, and in the majority of countries of the world, they have used the same method. It is evident, however, that in the mid-term and long-term planning, it is possible to consider other methods, if necessary and in accordance with the technical and developmental conditions of the country, in relation to the modification of the method and its modification.

As previously mentioned, today several regulations and guidelines for designing coastal structures among the world's technical communities have been used, including cases involving the United States, Britain, Germany, and Japan according to the history and records their empirical experience in marine industries is becoming more and more relevant. In the following, it attempts to summarize the outline of the factors influencing the process of examining and selecting an appropriate instruction within the framework of the objectives of the maritime organization's scheme and summarized it.

\subsection{American Maritime Code}

Among the countries involved in marine engineering, it is clear that the United States is at the top of its head in view of its remarkable advances, as well as large investments in 
research fields, in particular field and laboratory experiments related to marine engineering. This denied this. However, if the subject is viewed from the point of view of the Code of Practice or a coherent set of instructions, and at a glance at the usual situation in this regard, it will be seen that similar to many other technical matters of the country, a regulation or instruction in the form of a collection There is no single coherent design in coastal structures (15).

Obviously, this is not a scientific and technical disadvantage because the structure of technical affairs in this country, due to the existence of dozens of different scientific centers and different conditions in practice, which usually issues with the rules of designing is completely specialized Separated, but individually produced and supplied, and for their design teams, they have no particular problem in the United States because they are trained and trained for use in such a situation, requiring complicated and even impossible adjustments. Similar to other countries, this situation is unlikely. At the very least, if this is to be desired, it is likely that dozens of comparative actions in the philosophies governing each of their separate segments should be made, which would not be logical in the present circumstances. If we review the history of using US maritime law and regulations in Iran, it is clear that these uses are within the framework of designing a specific case, such as a platform or protective structure, and not in the form of a similar general project of port complexes.

Another distinction between American and European-specific guidelines is in the economic category, which means that Americans are, in principle, more deserving and, in view of their better economic situation (in the macro), they are inclined to come to an early conclusion if that Europeans are usually obsessed with their economic conditions, which remains a matter of technical regulations. Another notable issue is the US design standards for designing coastal structures related to the dating of these topics in that country. Therefore, according to recent materials and in the current situation, it is not possible to choose a coordinating code and guidelines in line with current needs of the country in the field of coastal structures design as a framework in the framework of various and different and, incidentally, American-style regulations. A recent study by Iranian consulting engineers over the past twenty years among Iranian marine engineering designers has suggested that US regulations should not be applied in the design of coastal structures, especially in the 
design of berths. However, the design of breakwaters is not the same and in this case, due to the good performance of the US Coast Guard Guidelines, it has been used extensively, but this one cannot resolve any other problems mentioned.

\subsection{British Maritime Code}

Considering the history of shipping in the UK, it is natural that the country expects to have extensive rules and regulations for marine engineering, which is, in fact, the same, and, like other BS-codes, and with titles and numbers, different coding has been developed and compiled. Of course, there is practically no complete and coherent set of rules for designing coastal structures, including all aspects related to the marine environment, but several parts of this country's standard on coastal structures design, which is the multiplicity of titles and the separation of some issues can make it difficult for users to use them outside of this country, which is, of course, a non-technical problem, but it still exists. But from a technical point of view, it can be admitted that the British marine engineering design standards are of high quality and have a good reputation, which, like all other matters, has specific features of the English type. For example, in some subjects, so much detail has been entered into the details that are also complex, which can almost be said that the principle of philosophy undermines the simplicity of an instruction, such as the discussion of the floating inhibition force and the design of the fender of the berths in operation it may be confusing the user and it is precisely the complex scientific-academic topics that take place in the context of a simple application that one instruction must have. This is the case and the case has been formulated and presented in most valid instructions in a fully functional, simple and correct way (16).

Another remarkable point about the structure and use of the British Codebook is that the two most important categories for the design of marine structures, namely the properties of consumer goods and the provision of statistical bases of waves as one of the loading phenomena, are integrated in the marine design section there is not enough, and it is almost dispersed that it can confuse the user and not forget that coherence in these cases will be the important benefits of a rule, especially if it is to be invoked in another country. Of course, 
it might be possible to combine the dispersed content of a very large set of BSs, but the points that are made about the coherence of a specialized setup will not be practically done correctly. Today, manufacturers of valid engineering codes know that dry provision of a set of rules cannot provide true users of that set; therefore, additional material on the basis of criteria and their clarity and the presentation of practical details in the form of interpretations and Technical notes add to the rules that have been widely welcomed by users over the past few years. Of course, one of the good advantages of the British Codebook has not passed, which is the presentation of some design details that can play a significant role in the design of the projects of a project, and these details have always been of interest to many engineers, especially young engineers who have little experience. A general assessment of the guidelines used by marine engineers in Iran indicates the importance of the British Maritime Code among engineers, but its use was very limited and limited for the reasons given.

\subsection{Japanese Coastal Designs Regulations 2002}

Based on the results of the evaluations carried out among marine engineer consultants at the end of the previous paragraph, it can be recognized relatively well that the most cited maritime regulations for the use of marine structures and, in principle, the design of coastal structures, rivers letter from Japan. Of course, it will be further understood that this experience is not so surprising. Perhaps the most important factor in the recent issue is the seismicity of the coasts of Japan and Iran, which naturally leads most design engineers to the Japanese regulations throughout the length of the regulations of Japan and in all its parts, it is easy to see the spirit of the rules and regulations related to earthquake issues and it is obvious that in such a situation and in a vacuum, a national and specialized code can be considered with a greater sense of security. To use the provisions of such a regulation, in particular the fact that in the 2002 edition of the by-laws, it published a considerable amount of material on the interpretation and technical specifications of the criteria set forth herein, which, as noted above, facilitates the use of better regulation and better understanding of the issues associated with them for the user, and this is a positive point. It can be as simple as it passed (17). 
Other important factors in using more than the Japanese regulations in our country can be the solid consistency of its contents in the form of a single collection, which unfortunately did not exist in the United States and British regulations (18).

Given the need for coherence between the various technical issues in an engineering branch that was discussed in detail in the past, it is easy to see this coherence in the diverse, but integrated, index of Japan. That is, almost all that is required as a designer for the design of coastal structures and their equipment is projected in this set and more interestingly, all is related to the marine environment, for example, when it comes to the properties of materials, that is, materials used in the marine environment, or when it comes to soil and soil, is entirely in the marine environment and its proximity, and this feature it is very important to use the code in a better way. The requirement to translate the Japanese text of the Japanese Maritime Code in English, which is practically translated into English because of its lack of English language, has led to the use of relatively simple and understandable sentences in its non-English-language versions (such as Iran ) and it's basically a pleasure for users. It is worth mentioning that in the introduction to the English translation of the Japanese Code, the authors have referred to the use of this code in other countries, and this suggests that Japanese researchers have used other engineers in their countries to comply with their criteria. This, of course, has had an impact on regulation so that it can also be used in designing coastal structures of other countries (19).

\subsection{Japanese Coastal Designs Regulations 2009}

In January 2009, a new edition of the Japanese Coastal Designs Regulations was published. Due to the importance of the issue and its impact on the choice of the rules for designing coastal structures in Iran, its comprehensive review was carried out by an expert group. Based on this assessment, it was found that the main difference between the new Japanese Decree (December 2009) and the 2002 edition is the philosophical attitude to design, which means that the spirit of the design criterion is based on performance-based design, which itself features is special. Basically, design based on performance has a completely different process than design based on permissible tension and limited stress, 
and the requirements of such design include completely non-existent and highly interpretive and qualitative topics. The subcategories of the design principles are based on performance in order to achieve its goals, including performance criteria, performance review, and design based on reliability. In addition to these main subcategories, interaction in defining and determining the levels of failure in functional classification in serviceability, repair, safety, and maintenance capabilities, as well as design control capabilities within the framework of reliability measures, on-line testing model, numerical methods and field experiments with different motivations for design engineers. Of course, in these cases, the need for an attitude to the random nature of most environmental loading, such as waves, earthquakes, and storms, should also be added (20).

It is worth noting that at present, all regulations and guidelines for the design of concrete and steel structures of the country are not designed in terms of performance. It is necessary to realize that the prediction of the related courses in the academic courses and the full knowledge of the graduates will now be such conditions are not considered. It is necessary to note that nearly $95 \%$ of the rules and regulations of the Japanese Coastal Construction Design Regulations 2002, in the form of design and control criteria, are still in the exact version of 2009, so the new edition of the new edition of an unconventional and totally transformed collection the 2002 edition is not changed, but the design attitude has changed (21).

According to the existing conditions and the necessity of providing a collection in the form of criteria for designing coastal structures, it seems appropriate that the 2002 edition continues to be the main basis, and in the future, with the provision of conditions for engineers graduating from University, design-based performance criteria are gradually being introduced into the scene (22).

\subsection{Other Maritime Regulations}

There are other regulations on the design of coastal structures, most of which have a specialized and relatively casual content, and do not have the necessary comprehension as a coherent code of design for coastal structures and are, in principle, tailored to the specific needs of custodians. Perhaps the most important of these is the German Maritime Code, but 
its contents are usually summarized (especially the loading section) and does not cover all marine matters, while in some structural cases it has the strengths to be mentioned in Its place can be fruitful (23).

Based on the evaluations carried out in the country's consulting firm's engineering experience, it has been observed that in very rare and exceptional cases, and in the form of a case study, these rules are used and, of course, by engineers who are familiar with the content. In the same way, as in the British Code, due to the lack of an earthquake in Germany, the vacuum of sufficient attention to this issue is evident in its terms (24).

\section{Conclusion}

In this research, after classification of the seas, lakes, wetlands, lagoons, and wetlands of the country, different types of beaches and their classification, the conditions of the coast of Iran were carried out, and then the most important components that should be considered when analyzing the features of a coastal site are as follows determination of project boundary and boundary conditions, meteorological information, hydrodynamic processes (wave height, tidal levels, flow velocity), seasonal variation of wave and current climate, topography and bulk, geomorphology and coastal sediment characteristics, determination of coastal sediment transport pattern, coastal changes, adverse effects specific environmental considerations (water quality, material evacuation, etc.), regional considerations (laws, seismicity, tsunami, flotation, etc.), geotechnical considerations, existing materials (sand resources, rock, etc.) and related requirements (resistance, durability, etc.), access to the site studied and monitoring the coastal protection plan. Then, the design conditions of the port and harbor facilities were determined from among the items listed below, taking into account the natural factors, conditions of construction and utilization, specifications of materials, environmental impacts and social requirements for the facilities to be selected: dimensions of the ship, foreign forces by ships, winds and wind pressure, waves and tidal forces, tidal waves and extreme sea levels, currents and current, external forces affecting their floating structures and their movement, river and coastal river hydropower, bedding, earthquakes and seismicity forces and fluidization, soil pressure and 
water pressure, dead weight and overhead, friction coefficient, other conditions essential for design. Finally, the Coastal Structures Design Regulation was obtained based on the documentation for the design of coastal structures. For many reasons, it was used to formulate comprehensive guidelines for the design of coastal structures in accordance with the comprehensive principles of Japan. But with all the positive qualities it seems, it is necessary to design a specific instruction of the country in Iran to be adapted to the environmental conditions. However, in the current context of using other guidelines as a basis, it is necessary for the academic education system to move in this direction and identify deficiencies and deficiencies of this alien instruction and rewrite them based on native features. Since one of the requirements of the instructions is its simplicity and comprehensiveness, and this study is not specialized in relations and calculations, it is suggested that in cases where complex and heavy mathematical calculations are required, references and authoritative sources provide these mathematical relationships.

\section{References}

Bijeny, B. (2011). Assessment and simulation of physical changes of the coastal region of Noshahr and Chalus using RS and GIS techniques and its adaptation to the principles of integrated coastal zone management (ICZM)," Master's thesis, Faculty of Arts and Architecture, Shiraz University, 2011.

B. Ramezani and M Taleghani. (2012). Approach to Integrated Environmental Management in the Organization of the Coast of the Country (Opportunities, Challenges and Solutions), Sepehr Geographical Information and Research Research Papers; 21 (84-1): 90-94.

M Sheikhi and M Azimi. (2013). Environmental management in coastal areas of cities with an emphasis on coastal management in the Caspian Sea. First National Conference on Geography, Urban Development and Sustainable Development, Tehran, Koomesh Environmental Society, Aviation Industry University.

B. Behnoud. (2014). Identifying the origin of sediments and estimating the sediment transport rate of the coast in less developed coastal areas of Sistan and Baluchestan province. Master thesis, University of Sistan and Baluchestan, Faculty of Engineering.

M Yousefi and P. Kordvani. (2014). Fluctuations in water level and Caspian Sea environment (coastline in Babolsar city)," Earth Knowledge Researches, Year 4, No. 41.

M Hossein Zadeh and. P. Khakpur. (2016). Sustainability zoning of Mahmoud Abad coastal zone through Coastal Vulnerability Index (CVI), Natural hazards, 5 (9). 
Van der Meer, Jentsje. (2017). Geometrical design of coastal structures. Dikes and Revetments: Design, Maintenance and Safety Assessment.

National Environmental Management: Air Quality Act. (2004). (Act no. 39 of 2004) Declaration of Greenhouse Gases As Priority Air Pollutants

National Environmental Management: Integrated Coastal Management Act. (2008). (Act No. 24 of 2008) Reclamation of land from Coastal Waters Regulations

Harper, B.A. (Ed.). (2001). Queensland cli-mate change and community vulnerability to tropical cyclones - ocean hazards assess-ment - stage 1. Report prepared by Systems Engineering Australia Pty Ltd in association with James Cook University Marine Mod-elling Unit, Queensland Government.

Webb T., R. Cox, T. Stul, D. Lord, P. Cummings, P. Nielsen, M. Townsend, and A. Gordon. (2014). NCCOE guidelines for managing climate change and climate variability in the coastal environment. Coast to Coast Conference, Australian Coastal Society, Mandurah WA, 6-14.

NCCOE (National Committee on Coastal and Ocean Engineering). (2012a). Guidelines for Responding to the Effects of Climate Change in Coastal and Ocean Engineering. Vol. 1 of Guideline Series, Engineers Aus-tralia, 3rd edition. 75 pp. Accessed 28 March 2016.

Gold Coast City Council/ (2013). Three Point Plan for Coastal Protection - City of Gold Coast and the Queensland Government. 20 pp. Accessed 28 March 2016.

GHD. (2012). Coastal Hazard Adaptation Strategy for Townsville City Council - Pilot project. Report prepared for Townsville City Council. 96 pp. Accessed 28 March 2016.

Moser, S.C., M. A. Davidson, P. Kirshen, P. Mulvaney, J. F. Murley, J. E. Neumann, L. Pe-tes, and D. Reed. (2014). Coastal zone devel-opment and ecosystems. Climate Change Impacts in the United States: The

Third Na-tional Climate Assessment, J. M. Melillo, T. C. Richmond, and G. W. Yohe, Eds., U.S. Global Change Research Program, 579-618. Accessed 28 March.

UK Environment Agency (UKEA). (2010). The Coastal Handbook: A guide for all those working on the coast. 220 pp. Accessed 28 March 2016.

Asada, Y., Hirasawa, Y. \& Nagasaki, F. (1983). Fishery Management in Japan. FAO Fisheries Technical Papers 238. 26p.

Ruddle, K. (1987). Administration and Conflict Management in Japanese Coastal Fisheries, FAO Fisheries Technical Paper, 273.

Yamamoto, T. (1995). Development of a Community-Based Fishery Management System in Japan, Marine Resource Economics, 10 (1), 21-34 
Uchida, Hirotsugu \& Wilen, James. (2004). Japanese coastal fisheries management and institutional designs: A descriptive analysis. Japan Proceedings.

Ministry of Agriculture, Forestry and Fisheries (MAFF). (2006). The 11th Fishery Census of Japan 2003. Tokyo.

Makino, M. \& Matsuda, H. (2005). Co-management in Japanese coastal fisheries: institutional features and transaction costs. Marine Policy 29(5): 441-450.

Li, C., and R. Cox. (2013). Stability of Hanbars for upgrading of breakwaters with sea level rise. Coasts and Ports. 21st Australasian Coast-al and Ocean Engineering Conference and the 14th Australasian Port and Harbour Conference. Barton, ACT, Engineers Australia, 477-482. Accessed 28 March.

LEE, Charles E. (1962). Recent Advances in Coastal Structure Design. Coastal Engineering Proceedings, (S.I.), n. 8, p. 23, jan. 